\title{
Child acceptability of a novel provitamin A carotenoid, iron and zinc-rich complementary food blend prepared from pumpkin and common bean in Uganda: a randomised control trial
}

\author{
Edward Buzigi ${ }^{1,2,3^{*}}$, Kirthee Pillay ${ }^{1}$ and Muthulisi Siwela ${ }^{1}$
}

\begin{abstract}
Background: Ugandan children are fed homemade complementary foods (CFs) which are usually deficient in vitamin A, iron and zinc. Novel homemade CFs rich in vitamin A, iron and zinc need to be developed, and assessed for their acceptability among target children.

Objective: Homemade provitamin A carotenoids (PVACS), iron and zinc-rich complementary food (CF), common bean pumpkin blend (BPB) formulated from pumpkin (Sweet cream) and common bean (Obwelu) and PVAC-rich pumpkin blend (PB) from Sweet cream were prepared by expert peer mothers. This study compared child acceptability of BPB and PB (control).

Methods: The crossover acceptability study randomly assigned Ugandan children 6 to 24 months old to either receive $100 \mathrm{~g}$ of BPB $(n=35)$ or $100 \mathrm{~g}$ of PB $(n=35)$ on day one. After a washout period of one day, children crossed over to receive either BPB $(n=35)$ or PB $(n=35)$. The amount of CF consumed, duration of consumption, and micronutrient intake were assessed. The CF was acceptable if children consumed $\geq 50 \mathrm{~g}(50 \%)$ of served food $(100 \mathrm{~g})$. A paired t-test was used to determine the mean differences within participants between BPB and PB. The level of statistical significant difference was set at a probability value of $5 \%(p=0.05)$.

(Continued on next page)
\end{abstract}

\footnotetext{
* Correspondence: edwardbuzigi@gmail.com

${ }^{1}$ Department of Dietetics and Human Nutrition, School of Agricultural, Earth and Environmental Sciences, University of KwaZulu-Natal, Private Bag X01, Scottsville 3209, Pietermaritzburg 3201, South Africa

${ }^{2}$ Health Economics and HIV/AIDS Research Division (HEARD), University of

KwaZulu-Natal, Westville Campus, J Block 4th Floor, Durban 4041, South

Africa

Full list of author information is available at the end of the article
}

C The Author(s). 2020 Open Access This article is licensed under a Creative Commons Attribution 4.0 International License, which permits use, sharing, adaptation, distribution and reproduction in any medium or format, as long as you give appropriate credit to the original author(s) and the source, provide a link to the Creative Commons licence, and indicate if changes were made. The images or other third party material in this article are included in the article's Creative Commons licence, unless indicated otherwise in a credit line to the material. If material is not included in the article's Creative Commons licence and your intended use is not permitted by statutory regulation or exceeds the permitted use, you will need to obtain permission directly from the copyright holder. To view a copy of this licence, visit http://creativecommons.org/licenses/by/4.0/ The Creative Commons Public Domain Dedication waiver (http://creativecommons.org/publicdomain/zero/1.0/) applies to the data made available in this article, unless otherwise stated in a credit line to the data. 
(Continued from previous page)

Results: The mean consumption of BPB and PB was $53.9 \mathrm{~g}$ and $54.4 \mathrm{~g}$, respectively. The mean duration for consumption of BPB and PB was 20.6 and 20.3 min, respectively. There was no significant difference in the amounts consumed, and duration of consumption in BPB and PB ( $p>0.05)$. The mean intake of vitamin A was significantly

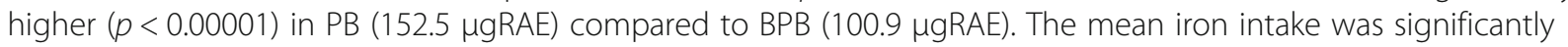
higher in BPB $(1.1 \mathrm{mg})(p<0.00001)$ compared to PB $(0.3 \mathrm{mg})$. Furthermore, zinc intake was significantly higher $(p<$ $0.00001)$ in BPB (0.58 mg) compared to PB (0.13 mg).

Conclusion: A homemade complementary food, BPB, made from locally available common bean and pumpkin is rich in PVACs, iron and zinc and is acceptable to children in the age range of complementary feeding in Uganda.

Trial registration: Pan African Clinical Trials Registry www.pactr.org as PACTR202002576768667.

Retrospectively registered.

Date of registration: 29/January/2020.

Keywords: Child acceptability, Complementary foods, Common bean pumpkin blend, Pumpkin blend, Provitamin A carotenoids, Iron, Zinc, Vitamin A, Uganda

\section{Background}

The burden of hidden hunger (micronutrient deficiencies) resulting from inadequate intakes of key micronutrients, particularly iron, zinc, and vitamin A, contributes to reductions in linear growth, vulnerability to infection, reduced cognitive function, and significant child morbidity and mortality in the developing world [1]. In developing countries, vulnerability to vitamin A deficiency iron deficiency and zinc deficiency begins during the period of complementary feeding, when children are fed complementary foods (CFs) deficient in vitamin $\mathrm{A}$, iron and zinc $[2,3]$.

The period of complementary feeding begins at 6 to 24 months or beyond, when nutritious homemade foods are supposed to be given alongside breast milk to meet the increased nutritional demands for a child's growth and development [4]. During the age range of complementary feeding, nutritional demands for vitamin A, iron and zinc increase [5-7], indicating that vitamin $A$, iron and zinc-rich CFs are necessary at this critical period of child growth and development [4]. However, in Uganda children are fed CFs, predominantly prepared from staple cereals and tubers such as white maize, cassava, sweet potatoes and yams [8]. Such staples are deficient in vitamin A, iron and zinc, and their consumption has been linked to deficiencies in vitamin A, iron and zinc [3]. A most recent study conducted in central rural Uganda, analysed the micronutrient content of CFs, and established that they were deficient in iron and vitamin A [9].

The World Health Organization (WHO) recommends that in order to combat micronutrient deficiencies such as vitamin $\mathrm{A}$, iron and zinc deficiencies child caregivers should feed their children CFs formulated from animal source foods, fortified foods and food supplements [4]. This is plausible because animal source foods, fortified foods and food supplements are rich sources of iron, zinc and vitamin A [10-14]. However, the rural poor including child caregivers in Ugandan are unable to physically access or afford animal source foods, fortified foods and food supplements $[15,16]$. Moreover, despite a high child vitamin A supplementation (VAS) coverage of over $65 \%$ in Uganda [17], the prevalence of vitamin A deficiency among Ugandan children less than five years old has unacceptably increased from $20.4 \%$ [18] to $32.6 \%$ [17] in the last decade. To this end, it is necessary to identify locally available and affordable food ingredients rich in vitamin $\mathrm{A}$, iron and zinc and use them to prepare CFs rich in vitamin A, iron and zinc to supplement on nutrition specific interventions such supplementation and fortification. Therefore, this study selected common bean, Obwelu and pumpkin, Sweet cream, locally cultivated in rural Uganda [19, 20], for use in the home preparation of a novel provitamin A carotenoids (PVACs), iron and zinc rich complementary food (CF). The former was selected because common bean is a rich source of iron and zinc [21-24], whilst the latter is a rich source of PVACs [25-27]. PVACs, are an inactive form of vitamin A predominantly found in plant food sources [28]. However, when PVACs-rich foods such as pumpkin are consumed, the PVACs are bioconverted into retinol, the active form of vitamin A used by the body [29].

Testing the acceptability of novel CFs is necessary because it is a measure that can inform whether caregivers will feed the CF to their children and whether children will accept to ingest the CF [30]. However, several studies have used child caregivers to test the acceptability of CFs [31-34], hence neglecting the target group for CFs, which are children 6 to 24 months old. Such studies argue that they prefer using caregivers to children because children are too young to provide a rational judgement on the sensory attributes such as taste, aroma, colour and texture, usually used to test for acceptability of foods [34]. However, caregiver acceptability of a CF does not guarantee child acceptability [35]. It is worth 
noting that child acceptability can be assessed by feeding the novel CF to the child, followed by measuring the amount of $\mathrm{CF}$ consumed, and the duration taken to complete the CF [36-39]. A novel PVACs, iron and zinc-rich homemade $\mathrm{CF}$, common bean pumpkin blend (BPB) prepared from locally available common bean and pumpkin in Uganda is acceptable to child caregivers [40]. However, child acceptability of BPB is unknown. Children 6 to 24 months old are the target consumers for CFs [41]. Therefore, this study assessed the acceptability of a novel multiple micronutrient rich homemade complementary food, BPB among Ugandan children in the age range of complementary feeding (6 to 24 months old).

\section{Methods}

\section{Study setting}

This study was conducted in rural Kyankwanzi district, central Uganda [42]. The total population of Kyankwanzi district is 214,693 , of which $34 \%$ are illiterate, $48 \%$ are females, $16 \%$ are child mothers $12-19$ years old and 19\% are children 0-4 years old [42]. Children in this study area are fed CFs deficient in vitamin $\mathrm{A}$, iron and zinc $[8$, 9]. The preparation of the CFs and child acceptability study were conducted at Ntwetwe Health Centre IV, Kyankwanzi district.

\section{Description of the intervention \\ Ingredients for preparation of the complementary foods used in the intervention}

This study formulated two homemade CFs, common bean pumpkin blend (BPB) and pumpkin blend (PB). The former was formulated from cooked common bean (Obwelu) and pumpkin (Sweet cream), whilst the latter (control CF) from cooked pumpkin, Sweet cream. The $\mathrm{PB}$ was selected as a control because pumpkin is commonly used as a single CF in Uganda [43].
These ingredients were chosen because common bean is rich in iron and zinc [21-24], and pumpkin is rich in PVACs [25-27]. Moreover, these ingredients are cultivated in rural Uganda and available in the local markets $[19,20]$. Figure 1 shows BPB, PB and ingredients, common bean (Obwelu) and pumpkin (Sweet cream) used to prepare $\mathrm{BPB}$ and $\mathrm{PB}$.

\section{Preparation of $B P B$ and $P B$}

At household level, caregivers usually prepare homemade CFs based on consistency (thinness and thickness) of the food and the child's age and development as recommended by the 2017 Food and Agriculture Organization of the United Nations (FAO) guide to conducting participatory cooking demonstrations to improve complementary feeding practices $[44,45]$. The 2017 FAO guide to conducting participatory cooking demonstrations to improve complementary feeding practices, encourages participatory cooking demonstrations involving community nutrition and health workers, mother-leaders and peer counsellors [44]. To this end, $\mathrm{BPB}$ and $\mathrm{PB}$ were prepared by child caregivers (expert peer mothers). Community health workers identified 10 expert peer mothers from the local community and invited them to Ntwetwe Health Centre IV to participate in the preparation of CFs used in the acceptability study. Expert peer mothers were encouraged to prepare CFs using the locally acceptable home-based methods used in the community to prepare common bean and pumpkin for child consumption.

Common bean (Obwelu) and pumpkin (Sweet cream) were purchased from the local market with assistance from expert peer mothers. Expert peer mothers prepared Sweet cream by peeling and discarding seeds followed by boiling the pulp. For Obwelu, expert peer mothers used overnight soaking (for about $8 \mathrm{~h}$ ), followed by boiling (for about $1.5 \mathrm{~h}$ ). After cooking, expert mothers

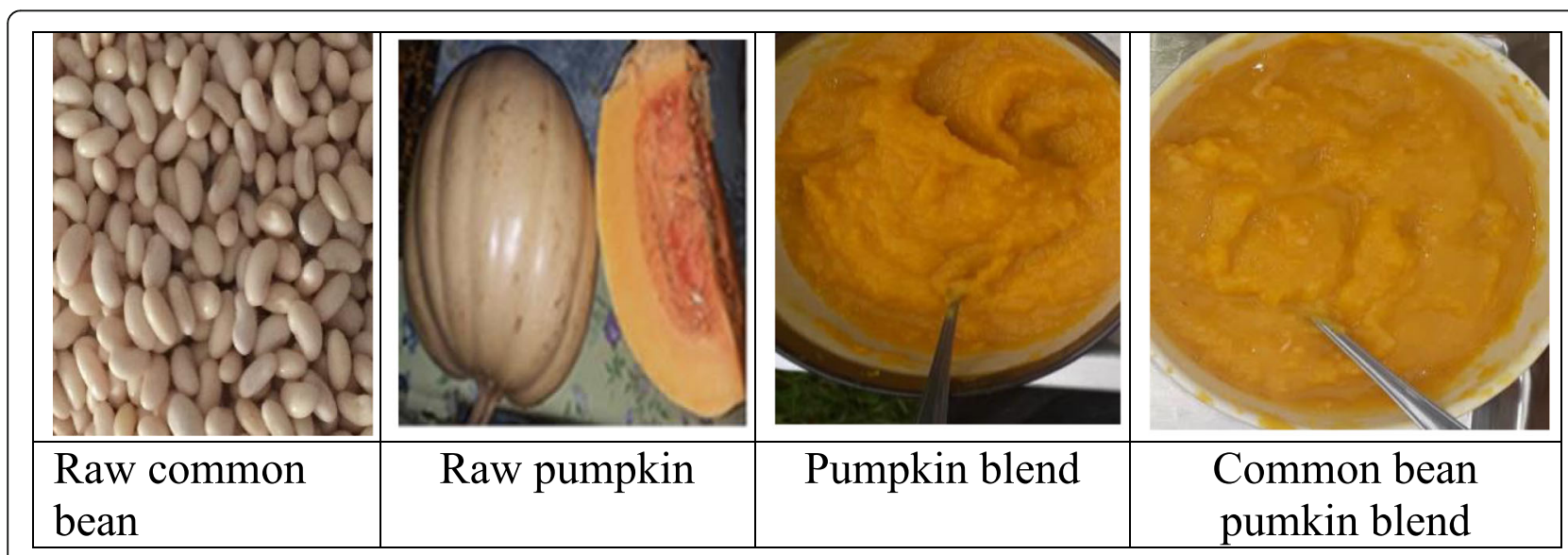

Fig. 1 Study complementary foods and their ingredients used to prepare them 
indicated that they prepare homemade CFs in their community based on consistency (thinness or thickness of food) suitable for the child's stage of development. To this end, after cooking by expert peers mothers, research assistants mixed the ingredients to form CFs based on the consistency as suggested by caregivers and recommended guidelines for conducting participatory cooking demonstrations to improve complementary feeding practices [44]. Research assistants prepared three different varieties of BPB by mixing and mashing Sweet cream and Obwelu together. Table 1 shows the ratio of mixing Sweet cream and Obwelu that was used to prepare BPB varieties.

After preparing, the three varieties of BPB were put on a table in three different serving dishes and presented to expert peer mothers. Based on consistency, expert mothers, one by one entered the room and where asked to choose one variety of BPB they would choose to feed their children, 6 to 24 months old [44]. All the 10 expert mothers unanimously selected BPB-3, prepared by mixing 2 parts of Sweet cream and 1 part of Obwelu. Mashed cooked pumpkin in Uganda is usually given as a single CF [43]. Therefore, pumpkin blend (PB) as a control was prepared from Sweet cream. Triplicate samples of prepared BPB (test food) and PB (control) were transported to METLAB East Africa limited laboratory, Kampala, Uganda for PVACs, iron and zinc analysis.

\section{Vitamin $A$, iron and zinc analysis of $B P B$ and $P B$}

The PVACs content was analysed by high performance liquid chromatography (HPLC) as described in the HarvestPlus hand book for carotenoid analysis [46]. To analyse the vitamin A content, the Institute of Medicine (2001) bioconversion rates of PVACs to vitamin A, retinol (retinol activity equivalents) were used, i.e. $12 \mu \mathrm{g}$ of $\beta$-carotene is equivalent to $1 \mu \mathrm{g}$ of retinol, whilst $24 \mu \mathrm{g}$ of $\alpha$-carotene is equivalent to $1 \mu \mathrm{g}$ retinol [47]. Iron and zinc concentrations of CFs were determined by flame atomic absorption spectroscopy (FAAS) as described elsewhere [9, 48]. Triplicate analysis for $\mathrm{BPB}$ and $\mathrm{PB}$ were done separately to get the mean content of PVACs, iron and zinc in each of the two CFs.

\section{Micronutrient composition of $B P B$ and $P B$}

The mean concentrations of PVACs, iron and zinc were calculated per $100 \mathrm{~g}$ of edible portion of CF. Table 2 shows the PVACs, iron, zinc and vitamin A content per $100 \mathrm{~g}$ of edible portion of BPB and PB.

Table 1 Ratio of mixing Sweet cream and Obwelu to formulate $\mathrm{BPB}$

\begin{tabular}{llll}
\hline BPB varieties & BPB -1 & BPB-2 & BPB-3 \\
\hline Sweet cream: Obwelu & $1: 1$ & $1: 2$ & $2: 1$ \\
\hline
\end{tabular}

BPB Common bean pumpkin blend
Table 2 Micronutrient composition of edible portion of BPB and PB

\begin{tabular}{lll}
\hline Micronutrient & $\mathrm{BPB} / 100 \mathrm{~g}$ & $\mathrm{~PB} / 100 \mathrm{~g}$ \\
\hline Iron $(\mathrm{mg})$ & 1.99 & 0.57 \\
Zinc $(\mathrm{mg})$ & 1.08 & 0.23 \\
$\beta$-carotene $(\mu \mathrm{g})$ & 2219 & 3326.5 \\
a-carotene $(\mu \mathrm{g})$ & 50.5 & 75.1 \\
Vitamin A, $\mu \mathrm{g}$ RAE & 187 & 280.3 \\
\hline
\end{tabular}

BPB Common Bean Pumpkin Blend; PB: Pumpkin Blend

RAE is Retinol activity equivalent (retinol)

$\operatorname{RAE}=\beta$-carotene $(\mu \mathrm{g} / 100 \mathrm{~g}) / 12+\alpha$-carotene $(\mu \mathrm{g} / 100 \mathrm{~g}) / 24$ [47]

\section{Study participants, enrolment, inclusion, and exclusion criteria}

All children (aged 6 to 24 months old) coming for growth monitoring and immunisation at Ntwetwe Health Centre IV, Kyankwanzi district Uganda were screened for nutritional status and presence of any illness. Upon fulfilling the enrolment criteria (age 6 to 24 months, on complementary feeding) and obtaining consent for participation from the caregivers, the children were randomly allocated to two different study groups (BPB and $\mathrm{PB}$ ) and children were enrolled. Children did not meet the enrolment criteria if their weight for age or weight for height $\mathrm{z}$-score was $<-3$ standard deviations, if they had any childhood acute illness or features suggestive of any chronic disease such as tuberculosis, any congenital anomalies such as cleft lip or palate.

\section{Sample size determination}

A maximum $50 \mathrm{~g}$ of CF per serving is considered adequate for children in the age range of complementary feeding [41, 49]. Therefore, the sample size was determined to test the hypothesis that the mean consumption of CF during the acceptability test would be at least $50 \mathrm{~g}$ (50\%) of the amount offered (100 g). Assuming a mean difference of $5 \mathrm{~g}$ between test CF and control, and a standard deviation (SD) of $10 \mathrm{~g}$ in a normally distributed population of children 6 to 24 months old, a sample size of 63 for each CF would therefore allow us to reject the null hypothesis with $80 \%$ power. However, this was a crossover study meaning that participants consumed both test CF and control. In order to cater for loss to follow-up, an additional seven participants were added to the 63 to make 70 participants. To this end, the same 70 participants were enrolled in each group of $\mathrm{BPB}$ and $\mathrm{PB}$.

\section{Study design}

This was a randomised crossover acceptability study. A total of 110 children from the growth monitoring and immunisation clinic at Ntwetwe Health Centre IV, Kyankwanzi district Uganda were identified for randomisation (Fig. 2). Out of the 110 children, 70 were eligible and assigned to BPB (intervention) and PB (control) 


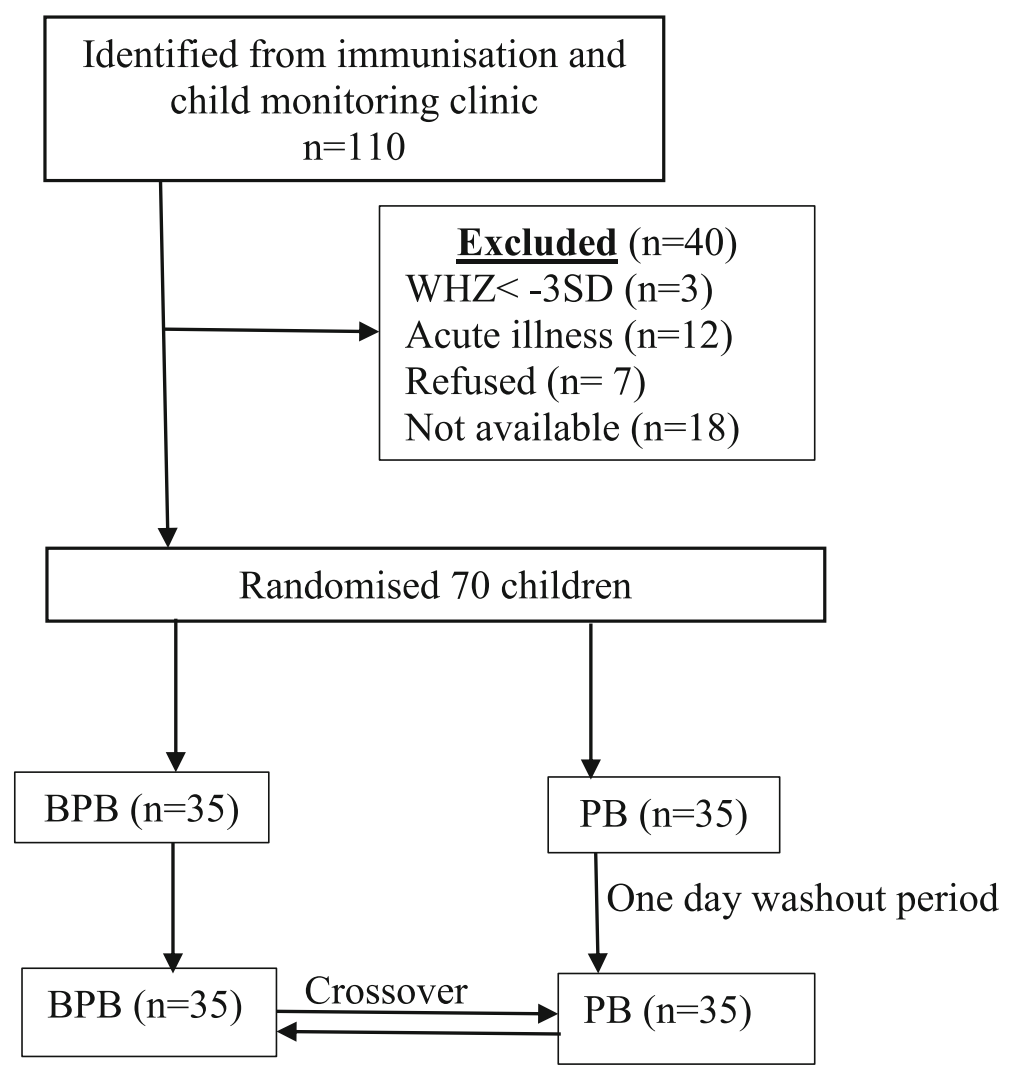

Fig. 2 Child acceptability study design

using simple random sampling according to computergenerated random numbers. Computer-generated numbers were given to participants by a research assistant who was located off site. On the first day, 35 children were assigned to each group of BPB and PB. A wash out period of one day was granted, and on the third day participants crossed over to the opposite CF group. Figure 2 shows the study design.

\section{Measurement of study outcomes}

Child acceptability was assessed by feeding the novel CF to the child, followed by measuring the amount of $\mathrm{CF}$ consumed, and duration taken to complete the CF [3639]. The primary outcome of the study was to measure the amount of CF consumed by children. The two secondary outcomes were to measure the time taken by the child to consume the served $\mathrm{CF}$; and to analyse the PVACs, iron and zinc intake of each child based on the amount of CF consumed. Caregivers were also requested to report any discomfort or adverse effects experienced by the children after being fed the study CFs.

\section{Amount of complementary food consumed by children}

This study ensured that children were offered the assigned $\mathrm{CF}$ (BPB or $\mathrm{PB}$ ) at least $1 \mathrm{~h}$ after they were last fed. A portion of $100 \mathrm{~g}$ of CF was offered to the child in a serving dish by the caregiver. The $\mathrm{CF}$ was considered acceptable if the child ingested at least $50 \mathrm{~g}$ of offered food [41]. The amount of food ingested was calculated by subtracting the left-over from the offered amount. Pre-weighed napkins were provided; any food that was regurgitated, vomited or spilled was swabbed, the napkin weighed and subtracted from the weight of the amount offered.

\section{Duration of feeding}

Duration of feeding was measured as described elsewhere [36]. Caregivers were asked to spoon feed their children the assigned CF until the child refused to eat. After a two-minute pause, the same food was offered a second time until s/he refused again. After a second two-minute pause, the food was offered a third time until refused again. After this third refusal, the feeding episode was considered terminated. The duration of feeding (excluding the intervening 'pause periods') was recorded by stopwatch, and the total duration of the feeding was noted. The feeding episode took place under the direct supervision of a trained research assistant to ensure that feeding was not forced. Children were considered as refusing intake if they moved their head away 
from the food, cried, clamped the mouth shut or clenched the teeth, or became agitated, spat out the food or refused to swallow as done elsewhere [36].

\section{Micronutrient intake measurement}

The micronutrient intake (MNI) for each child was calculated using the formula, $\mathrm{MNI}=\mathrm{A}(\mathrm{g}){ }^{*} \mathrm{~B} / 100$, where $\mathrm{A}$ was the amount of $\mathrm{CF}$ ( $\mathrm{BPB}$ or $\mathrm{PB}$ ) consumed by the child and $\mathrm{B}$ was the nutrient composition in $100 \mathrm{~g}$ of $\mathrm{CF}$ food served to the child (see Table 2). For example, if the child consumed $50 \mathrm{~g}$ of $100 \mathrm{~g}$ of BPB served, then MNI for iron, zinc and vitamin A would be $50^{*} 1.99 / 100$ (0.995 mg), 50*1.08/100 (0.54 mg) and 50*187/100 (93.5 $\mu \mathrm{gRAE})$, respectively.

\section{Measurement of background characteristics}

Data on background characteristics such as age, gender and nutritional status of study participants were collected. Age was calculated in months based on the difference between the date of visit and date of birth. If exact date of birth of the child was unknown, the month and year of birth were estimated using a local events calendar. In such cases, age was calculated after imputing the day of birth as the 15th of the month, as recommended by 2019 WHO guidelines [50]. Date of birth was extracted from the child's immunisation and growth monitoring chart. Nutritional status was determined using anthropometry, and diagnosed by $\mathrm{Z}$ scores based on the 2019 WHO recommendations for data collection, analysis and reporting on anthropometric indicators in children under 5 years old [50]. A child was stunted, wasted and underweight if his or her length for age $\mathrm{Z}$ score (LAZ), weight for length $Z$ score (WLZ) and weight for age $Z$ score (WAZ) was below -2 standard deviations of the WHO reference respectively [51].

\section{Data analysis}

Statistical and data analysis was done by STATA version 13.1. Background characteristics of the participants were evaluated by using descriptive statistics. The mean \pm SD of the amount of the CF consumed, duration of consumption, and MNI was calculated. The paired t-test was used to detect the mean differences of outcome variables within participants between BPB and PB. The level of significant difference was set at a probability value of $5 \%(p 0.05)$.

\section{Ethical approval}

Permission to conduct the study was granted by the District Health Office, Kyankwanzi district, Uganda. In South Africa, ethical approval was obtained from the Biomedical Research Ethical Committee, University of KwaZulu-Natal, South Africa (Reference number: BE 438/19). In Uganda, ethical approval was granted by The
AIDS Support Organisation Research Ethical Committee (Reference number: TASO-REC/066/19-UG-REC-009). This randomised control trial was registered by Pan African Clinical Trials Registry (www.pactr.org) as PACT R202002576768667. Informed and signed consent were obtained individually from caregivers of child participants in the study, and all data were coded to remove identifying information and ensure confidentiality.

\section{Results}

\section{Description of study participants}

On day one, 35 children were either fed on BPB or PB, day two was a wash out period. On day three, 35 participants crossed to receive either $\mathrm{BPB}$ or $\mathrm{PB}$. A total of 70 eligible children were enrolled and completed the acceptability test. They included 37 girls $(52.9 \%)$ and 33 boys (47.1\%), and their mean age \pm SD was $12.3 \pm 3.9$ months. The proportion of wasting, underweight and stunting among study participants was 7, 17 and 29.3\%, respectively. Caregivers did not observe any discomforts or adverse effects from their children after tasting BPB or $\mathrm{PB}$. The mean age and SD of child caregivers was 23.6 years and 6.1, respectively. Of the 70 caregivers, 63 (90\%) and 7 (10\%) caregivers were females and males, respectively. Table 3 shows the socio-demographic characteristics and nutritional status of child participants.

\section{Acceptability test}

The aim of this study was to assess the acceptability of a novel homemade complementary food (BPB), rich in PVACs, iron and zinc, compared to PVAC-rich $\mathrm{PB}$

Table 3 Socio-demographic characteristics and nutritional status of the acceptability study child participants

\begin{tabular}{ll}
\hline Characteristics & Participants $(n=70)$ \\
\hline Socio-demographic & $12.3 \pm 3.9$ \\
Age (months), mean \pm SD & \\
Gender & $38(54.3)$ \\
Female, $n(\%)$ & $32(45.7)$ \\
Male, $n$ (\%) & \\
Nutritional status & \\
Wasted & $5(7.1)$ \\
Yes, $n(\%)$ & $65(92.9)$ \\
No, $n$ (\%) & \\
Underweight & $8(11.4)$ \\
Yes, $n(\%)$ & $62(88.6)$ \\
No, $n$ (\%) & \\
Stunting & $27(38.6)$ \\
Yes $n$ (\%) & $43(61.4)$ \\
No $n$ (\%)
\end{tabular}

SD Standard deviation 
(control). Acceptability was measured by the amount of CF consumed by the child and duration of consumption. Table 4 shows results from the child acceptability test.

\section{Amount of complementary food consumed}

Children consumed on average $54.2 \pm 3.3 \mathrm{~g}$ of served food. The mean consumption of $\mathrm{BPB}$ and $\mathrm{PB}$ was $53.9 \mathrm{~g}$ and $54.4 \mathrm{~g}$, respectively. There was no significant difference in the amount consumed between the multiple micronutrient test $\mathrm{CF}$ and control CF $(p=0.44)$. The CF was acceptable if the child ate $50 \mathrm{~g}$ (50\% and above) of the $100 \mathrm{~g}$ of CF offered. To this end, both BPB and PB were $100 \%$ acceptable to the study children.

\section{Duration of consumption of BPB and PB}

The mean duration for consumption of $\mathrm{BPB}$ was slightly longer $(20.6 \mathrm{~min})$ compared to PB (20.3 min). However, there was no significant difference in mean duration of consumption for $\mathrm{BPB}$ and $\mathrm{PB}(p=0.14)$.

\section{Vitamin A, iron and zinc intake from consumed BPB and PB}

The mean vitamin A (retinol) intake was $100.9 \mu \mathrm{gRAE}$ and $152.5 \mu \mathrm{gRAE}$ in $\mathrm{BPB}$ and $\mathrm{PB}$, respectively. The mean intake of vitamin A was significantly higher in $\mathrm{PB}$ compared to BPB $(p<0.00001)$. The mean iron intake was significantly $(p<0.00001)$ higher in BPB $(1.1 \mathrm{mg})$ compared to $\mathrm{PB}(0.3 \mathrm{mg})$. Furthermore, zinc intake was significantly higher in $\mathrm{BPB}(0.58 \mathrm{mg})$, compared to $\mathrm{PB}$ (0.13 mg).

\section{Discussion}

Expert peer mothers formulated a multiple micronutrient CF, BPB, rich in PVACs, iron and zinc, based on locally available, culturally acceptable food ingredients, that is, pumpkin and common bean based on the guide to conducting participatory cooking demonstrations to improve complementary feeding practices [44]. Provitamin A carotenoids are an inactive form of vitamin A $[29,47]$. To this end, this study included the vitamin A content of CFs based on the 2001 Institute of Medicine bioconversion rates of PVACs to retinol, an active form of vitamin A used by the body [47]. Common bean pumpkin blend was superior in iron and zinc compared to $\mathrm{PB}$ because of the common bean mixed with pumpkin to form BPB (see Table 2). This is plausible because common bean is a rich source of iron and zinc [21-24]. Besides, PB was superior in vitamin A because $100 \%$ of PB was prepared from pumpkin, a rich source of PVACs [25-27].

The average recommended amount of CF per serving for a child, 6 to 24 months old during complementary feeding is $50 \mathrm{~g}$ [49]. The hypothesis was that the CFs would be acceptable if children consumed $50 \mathrm{~g}$ or more of the offered CF. The mean amount consumed of both CFs was above $50 \mathrm{~g}$, indicating that both CFs were $100 \%$ acceptable. Moreover, there was no significant difference in the mean amount consumed between the BPB and PB.

Preparation and acceptability of micronutrient-rich CFs from locally available food ingredients has been reported previously [32, 33, 51, 52]. Based on the amount consumed, Bauserman and colleagues established that micronutrient-rich $\mathrm{CF}$ prepared from caterpillar, corn and palm oil was acceptable to children in the age range of complementary feeding, in the Democratic Republic of Congo [51]. Bauserman and colleagues developed the $\mathrm{CF}$ in accordance with the international standards on the formulation of foods intended for infants and children up to 2 years of age as outlined in Codex Alimentarius [41, 51]. However, this present study developed CFs based on consistency as determined by child caregivers and as recommended in the preparation of homemade CFs [44]. Preparation in accordance with the international standards on the formulation of foods intended for infants and children up to 2 years of age outlined in the Codex Alimentarius is more objective to nutrient content of CFs, compared to the subjective method of using consistency. This may explain why the iron and zinc content in the study by Bauserman and colleagues is higher than that in BPB [51]. The vitamin A (in the form of retinol activity equivalent), iron and zinc content of BPB was reported in this study. However, Bauserman and colleagues only reported zinc and iron content of their $\mathrm{CF}$, despite the use of PVAC-rich palm oil as one of the ingredients in the formulation of the CF $[28,51]$. Therefore, it is difficult to conclude the

Table 4 Child acceptability and micronutrient intake between BPB and PB

\begin{tabular}{llll}
\hline Variable & BPB $(n=70)$ & PB $(n=70)$ & $p$ value \\
\hline Amount consumed, g (mean \pm SD) & $53.9 \pm 2.97$ & $54.4 \pm 3.51$ & 0.44 \\
Feeding duration, minutes (mean \pm SD) & $20.6 \pm 1.4$ & $20.3 \pm 1.6$ & 0.14 \\
Iron received in consumed food, mg (mean \pm SD) & $1.1 \pm 0.59$ & $0.3 \pm 0.02$ & $<0.00001$ \\
Vitamin A received in consumed food, $\mu$ g RAE (mean \pm SD) & $100.9 \pm 0.7$ & $152.5 \pm 1.2<<0.00001$ \\
Zinc received in consumed food, mg (mean \pm SD) & $0.58 \pm 0.04$ & $0.13 \pm 0.01<$ & $<0.00001$ \\
\hline
\end{tabular}

BPB Common Bean Pumpkin Blend, PB Pumpkin Blend, SD Standard Deviation $\mu g R A E$ Microgram Retinol Activity Equivalent (Retinol, Vitamin A) 
vitamin A content in the CF developed by Bauserman and colleagues [51].

In Kenya, the highest proportion of children aged 6 to 24 months old consumed over $75 \%$ of the CF developed from locally available termites and small fish, which was regarded as acceptable [52]. However, the Kenyan study also reported the estimated content of iron and zinc, but not vitamin A. In South Africa, CFs, were developed from provitamin A-biofortified foods [32, 33]. However, these studies did not test the acceptability of these CFs in the target age group (children 6 to 24 months old) of complementary feeding $[32,33]$. In contrast to other previous studies [32, 33, 51, 52], this study developed a multiple micronutrient $\mathrm{CF}$ rich in vitamin $\mathrm{A}$, iron and zinc, and tested its acceptability among children in age of complementary feeding. It is worth noting that vitamin A, iron and zinc are the leading three micronutrients of public health importance in the developing world needed to prevent child morbidity and the common childhood morbidities such as diarrhoea, respiratory tract infections, night blindness, and iron deficiency anaemia [1]. To this end, formulating and testing child acceptability of a PVACs, iron and zinc rich $\mathrm{BPB}$ was necessary in the developing country, Uganda.

The role of CFs in meeting the dietary reference intakes such as the recommended dietary allowance (RDA) for children in the age range of complementary feeding is well recognised [53]. The RDA is the intake that meets the nutrient need of almost all (97 to 98\%) individuals in a group [47]. The RDA for retinol (vitamin A), iron and zinc for a child 13 to 24 months old is 300 $\mu \mathrm{gRAE} /$ day, $7 \mathrm{mg} /$ day and $3 \mathrm{mg} /$ day, respectively [47]. This study showed that the average intake of vitamin A, iron and zinc in one serving from BPB was $109.5 \mathrm{mg}$, $1.1 \mathrm{mg}$ and $0.58 \mathrm{mg}$, respectively. This suggests that one serving of BPB would contribute 37, 16 and 19\% towards meeting the RDA for vitamin A, iron and zinc, respectively in children 13 to 24 months old. It is worth noting that $100 \mathrm{~g}$ of cooked common bean used to prepare BPB contains $7.1 \mathrm{mg}$ and $2.7 \mathrm{mg}$ of iron and zinc, respectively [54]. This suggests that pumpkin mixed with common bean to formulate the BPB variety selected by mothers reduced iron and zinc content of common bean by $5 \mathrm{mg}$ and $1.7 \mathrm{mg}$, respectively.

If $\mathrm{BPB}$ was served to children twice daily, it would contribute 74, 32 and 38\% towards meeting the RDA for vitamin $\mathrm{A}$, iron and zinc, respectively in children under study. It is worth noting that provitamin A-biofortified food crops such as maize and orange-fleshed sweet potato are bred to provide $50 \%$ of the mean daily vitamin A dietary requirement through normal consumption habits $[55,56]$. However, BPB that is served twice daily would provide over $50 \%$ of the mean daily vitamin A RDA for a child, 13 to 24 months old. Iron and zinc concentration of BPB was low compared to other studies that developed and tested child acceptability of iron and zinc-rich complementary foods [51, 52]. However, there is convincing evidence from a systematic review study that low dose daily iron and zinc intake has a positive effect on iron and zinc status of children, 6 to 24 months old [57].

It is worth noting that the rural poor in Uganda feed their children CFs such as staple cereals and tubers, which are deficient in vitamin A $[8,9]$, because they lack physical and economic access to vitamin A-rich foods such as animal source foods and vitamin A-fortified foods [15]. To contribute towards combating vitamin A deficiency among in Ugandan children, bi-annual (6 monthly) high dose (200,000 IU or $60,000 \mu \mathrm{gRAE})$ VAS programmes have been running for more than a decade $[17,58,59]$. However, the prevalence of child vitamin A deficiency in Uganda has increased from 20.4\% [18] to $32.6 \%$ [17] in the last decade. This is plausible because standalone VAS programmes may not combat vitamin A deficiency [60], because the liver is unable to store the high dose of $60,000 \mu \mathrm{g}$ retinol (200 times the RDA for a child 12 to 24 months old), and therefore, the excess vitamin A is destroyed by the liver and excreted [61]. Moreover, the rise in serum retinol resulting from 6monthly VAS is small, short-lived, and lasts only for 1 to 3 months [62]. To this end, a PVACs, iron and zinc rich $\mathrm{BPB}$ or a PVAC-rich PB may be necessary to complement VAS programmes in the fight against child vitamin A deficiency in Uganda.

\section{Strengths and limitations of the study}

Bioavailability is defined as the proportion of the ingested nutrients that are absorbed in the small intestine, enter the circulation, and become available for utilization or storage in organs [63]. This study did not analyse for the anti-nutrient compounds such as phytic acid in BPB. It is worth noting that common bean, an ingredient of BPB is a potential source of phytic acid, an anti-nutrient that reduces the bioavailability of iron and zinc $[2,64]$. However, common home cooking methods such as soaking and boiling used in this study reduce the amounts of phytic acid in common bean [65]. Moreover, zinc absorption is not associated with dietary phytic acid intake in infants and young children in the age range of complementary feeding [66]. Furthermore, PVACs are fat soluble [63], and therefore, incorporating fat during preparation of $\mathrm{BPB}$ or $\mathrm{PB}$ could have improved their PVACs bioavailability. However, the widely accepted 2001 Institute of Medicine bioconversion recommendations of PVACs to retinol used in this this study are independent of the use of fat as an ingredient in the preparation of PVACs-rich foods [47]. Furthermore, this present study considered that 
the offered CF was acceptable to children, 6 to 24 months old, if they ingested at least $50 \mathrm{~g}$ of the CF offered. This is in line with the 2013 FAO and WHO guidelines on formulated CFs for older infants and young children, which considers $50 \mathrm{~g}$ of offered CF as a reasonable maximum quantity which children in the age range of complementary feeding can ingest per feeding [41]. However, child acceptability findings from the present study with regard to the amount of CF ingested in a specified duration should be interpreted with caution. This is because a wide range of $10 \mathrm{~g}$ to $50 \mathrm{~g}$ of a formulated CF is considered a reasonable quantity an older infant or a young child in the complementary feeding stage can ingest easily in one feeding session for a specified duration, depending on age [41]. Therefore, older infants (6 to 12 months old) may ingest less CF in a specified duration than young children (13 to 24 months old).

\section{Conclusion}

Expert peer mothers (child caregivers) developed a PVACs, iron and zinc-rich complementary food, BPB based on locally available pumpkin and common bean by using home preparation methods. The newly developed, multiple micronutrient rich BPB is acceptable to children in the age range of complementary feeding, and has the potential to contribute towards combating deficiencies in vitamin $\mathrm{A}$, iron and zinc among children aged 6 to 24 months old.

\section{Abbreviations \\ BPB: Common Bean Pumpkin Blend; CF: Complementary Food: CFs: Complementary Foods; MNI: Micronutrient Intake; PB: Pumpkin Blend; PVACs: Provitamin A Carotenoids; RAE: Retinol Activity Equivalent; RDA: Recommended Dietary Allowances; SD: Standard Deviation; VAS: Vitamin A Supplementation}

\section{Acknowledgments}

The authors would like to thank the Health Economics and HIV/AIDS Research Division (HEARD), University of KwaZulu-Natal, South Africa for the financial assistance during the study. The authors are grateful to the village team members, research assistants, expert peer months and child caregivers who participated in the study.

\section{Authors' contributions}

EB, KP and MS conceptualized the study; EB analysed the data and wrote the first draft of the manuscript; KP and MS reviewed and edited the draft of the manuscript. All authors have edited, read and approved the final manuscript.

\section{Funding}

This work was funded by the Health Economics and HIV/AIDS Research Division (HEARD), University of KwaZulu-Natal, South Africa. The funder has financially supported the process of data collection. The funder had no role in study design, data collection and analysis, decision to prepare or publish the manuscript.

\section{Availability of data and materials}

The datasets used and/or analysed during the current study are available from the corresponding author on reasonable request.

\section{Ethics approval and consent to participate}

Permission to conduct the study was granted by the District Health Office Kyankwanzi district, Uganda. Ethical approval was obtained from Biomedical Research Ethical Committee, University of KwaZulu-Natal, South Africa (Reference number: BE 438/19). In Uganda, ethical approval was granted by The AIDS Support Organisation Research Ethical Committee (Reference number, TASO-REC/066/19-UG-REC-009). Informed and signed consent were obtained individually from the caregivers of the participants in the study, and all data were coded to remove identifying information and secure confidentiality.

Consent for publication

Not applicable.

\section{Competing interests}

The authors declare that they have no competing interests.

\section{Author details}

'Department of Dietetics and Human Nutrition, School of Agricultural, Earth and Environmental Sciences, University of KwaZulu-Natal, Private Bag X01, Scottsville 3209, Pietermaritzburg 3201, South Africa. ${ }^{2}$ Health Economics and HIV/AIDS Research Division (HEARD), University of KwaZulu-Natal, Westville Campus, J Block 4th Floor, Durban 4041, South Africa. ${ }^{3}$ Department of Human Nutrition \& Home Economics, Kyambogo University, P.O. Box 1 Kyambogo, Kampala, Uganda.

Received: 24 January 2020 Accepted: 27 August 2020

Published online: 01 September 2020

\section{References}

1. Millward DJ. Nutrition, infection and stunting: the roles of deficiencies of individual nutrients and foods, and of inflammation, as determinants of reduced linear growth of children. Nutr Res Rev. 2017;30:50-72.

2. Gibson RS, Bailey KB, Gibbs M, Ferguson EL. A review of phytate, iron, zinc, and calcium concentrations in plant-based complementary foods used in low-income countries and implications for bioavailability. Food Nutr Bull. 2010;31 2 (supplement):134-146.

3. Gegios A, Amthor R, Maziya-Dixon B, Egesi C, Mallowa S, Nungo R, et al. Children consuming cassava as a staple food are at risk for inadequate zinc, iron, and vitamin a intake. Plant Foods Hum Nutr. 2010;65:64-70.

4. WHO. Infant and young child feeding: Model Chapter for textbooks for medical students and allied health professionals. Geneva: WHO; 2009. https://apps.who.int/iris/bitstream/handle/10665/44117/9789241597494_ eng.pdf? sequence=1.

5. Dorea JG. Iron and copper in human milk. Nutrition. 2000;16:209-20.

6. Sakurai T, Furukawa M, Asoh M, Kanno T, Kojima T, Yonekubo A. Fat-soluble and water-soluble vitamin contents breast Milk from Japanese women. J Nutr Sci Vitaminol. 2005;51:239-47.

7. Qian J, Chen T, Lu W, Wu S, Zhu J. Breast milk macro- and micronutrient composition in lactating mothers from suburban and urban Shanghai. J Paediatr Child Health. 2010;46:115-20.

8. Amaral MM, Herrin WE, Gulere GB. Using the Uganda National Panel Survey to analyze the effect of staple food consumption on undernourishment in Ugandan children. BMC Public Health. 2018;18.

9. Ekesa B, Nabuuma D, Kennedy G. Content of iron and vitamin a in common foods given to children 12-59 months old from North Western Tanzania and Central Uganda. Nutrients. 2019;11.

10. Dror DK, Allen LH. The importance of milk and other animal-source foods for children in low-income countries. Food Nutr Bull. 2011;32:227-43.

11. Dary $\mathrm{O}$, Mora JO. Food fortification to reduce vitamin a deficiency : international vitamin a consultative group recommendations. J Nutr. 2002; 132:2927S-33S

12. Shah D, Sachdev HS, Gera T, De-Regil L, Peña-rosas J p. Fortification of staple foods with zinc for improving zinc status and other health outcomes in the general population. Cochrane Database Syst Rev. 2016;:Art. No.: CD010697.

13. Bhutta ZA, Bird SM, Black RE, Brown KH, Gardner JM, Hidayat A, et al. Therapeutic effects of oral zinc in acute and persistent diarrhea in children in developing countries : pooled analysis of randomized controlled trials. Am J Clin Nutr. 2000;72:1516-22. 
14. Lukacik M, Thomas RL, Aranda JV. A meta-analysis of the effects of Oral zinc in the treatment of acute and persistent diarrhea. Peadiatrics. 2008;121:32636.

15. Wamani H, Strøm ANA, Peterson S, Tylleskar T, Tumwine JK. Infant and Young Child Feeding in Western Uganda : Knowledge, Practices and Socioeconomic Correlates. J Trop Pediatr. 2005:51:356-61.

16. Faber M. Perceptions of infant cereals and dietary intakes of children aged 4-24 months in a rural South African community. Int J Food Sci Nutr. 2001; 52:359-65.

17. Wirth JP, Petry N, Tanumihardjo SA, Rogers LM, Mclean E, Greig A, et al. Vitamin a supplementation programs and country-level evidence of vitamin a deficiency. Nutrients. 2017:9:1-18.

18. Baingana RK, Matovu DK, Garrett D. Application of retinol-binding protein enzyme immunoassay to dried blood spots to assess vitamin a deficiency in a population-based survey : the Uganda demographic and health survey 2006. Food Nutr Bull. 2008;29:297-305.

19. Kiwuka C, Bukenya-Ziraba R, Namaganda M, Mulumba JW. Assessment of common bean cultivar diversity in selected communities of Central Uganda. Afr Crop Sci J. 2012;20:239-49.

20. Nakazibwe I, Wangalwa R, Olet EA, Kagoro GR. Local knowledge of pumpkin production, performance and utilization systems for value addition avenues from selected agro-ecological zones of Uganda. Afr J Agric Res. 2019;14: 1509-19. https://doi.org/10.5897/AJAR2019.14070.

21. Carvalho L, Corrêa M, Pereira E, Nutti M, Carvalho JV, Ribeiro EG, et al. Iron and zinc retention in common beans (Phaseolus vulgaris L.) after home cooking. Food. Nutr Res. 2012:56:15618.

22. Ferreira AST, Naozuka J, Kelmer GAR, Oliveira PV. Effects of the domestic cooking on elemental chemical composition of beans species ( Phaseolus vulgaris L.). J Food Process. 2014;2014:1-6.

23. Moloto RM, Moremi LH, Soundy P, Maseko ST. Biofortification of common bean as a complementary approach to addressing zinc deficiency in south Africans. Acta Agric Sect B-Soil Plant Sci. 2018;68:575-84.

24. Haas JD, Luna SV, Lung MG, Wenger MJ, Murray-kolb LE, Beebe S, et al. Consuming Iron biofortified beans increases Iron status in Rwandan women after 128 days in a randomized controlled feeding trial. J Nutr. 2016;146: 1586-92.

25. Azevedo-Meleiro CH, Rodriguez-Amaya DB. Qualitative and quantitative differences in carotenoid composition among Cucurbita moschata, Cucurbita maxima, and Cucurbita pepo. J Agric Food Chem. 2007:55:402733.

26. Azizah AH, Wee KC, Azizah O, Azizah M. Effect of boiling and stir frying on total phenolics, carotenoids and radical scavenging activity of pumpkin (Cucurbita Moschato). Int Food Res J. 2009;16:45-51.

27. Koh SH, Loh SP. In vitro bioaccessibility of $\beta$-carotene in pumpkin and butternut squash subjected to different cooking methods. Int Food Res J. 2018;25:188-95

28. Codjia G. Food sources of vitamin a and provitamin a specific to Africa : an FAO perspective. Food Nutr Bull. 2001;22:357-60.

29. Van-Loo-Bouwman CA, Naber THJ, Schaafsma G. A review of vitamin a equivalency of $\beta$-carotene in various food matrices for human consumption. Br J Nutr. 2014;111:2153-66.

30. Skinner JD, Carruth BR, Bounds W, Ziegler PJ. Children's food preferences: a longitudinal analysis. J Am Diet Assoc. 2002;102:1683-47.

31. Pillay K, Khanyile N, Siwela M. Acceptance of an orange-fleshed sweet potato complementary food by infant caregivers in KwaZulu-Natal Province - a preliminary study. S Afr J Child Heal. 2018;12:100-4.

32. Amod R, Pillay K, Siwela M, Kolanisi U. Acceptance of a complementary food based on Provitamin A- biofortified maize and chicken Stew. J Hum Ecol. 2016;55:152-9.

33. Govender L, Pillay K, Derera J, Siwela M. Acceptance of a complementary food prepared with yellow, provitamin A-biofortified maize by black caregivers in rural KwaZulu-Natal. S Afr J Clinc Nutr. 2014;27:217-21.

34. Martin H, Laswai H, Kulwa K. Nutrient content and acceptability of soybean based complementary food. Afr J Food Agric Nutr Dev. 2010;10:2040-9. https://doi.org/10.4314/ajfand.v10i1.51482.

35. Paul KH, Dickin KL, Ali NS, Monterrosa EC, Stoltzfus RJ. Soy- and Rice-based processed complementary food increases nutrient intakes in infants and is equally acceptable with or without added Milk powder. J Nutr. 2008;138: 1963-8.

36. Ahmed T, Choudhury N, Hossain MI, Tangsuphoom N, Islam MM, de Pee S, et al. Development and acceptability testing of ready-to-use supplementary food made from locally available food ingredients in Bangladesh. BMC Pediatr. 2014:14.

37. Adu-Afarwuah S, Lartey A, Brown KH, Zlotkin S, Briend A, Dewey KG. Home fortification of complementary foods with micronutrient supplements is well accepted and has positive effects on infant iron status in Ghana. Am J Clin Nutr. 2008;87:929-38.

38. Guinard J. Sensory and consumer testing with children. Trends Food Sci Technol. 2001;11:273-83.

39. Aaron GJ, Lo NB, Hess SY, Guiro AT, Wade S, Ndiaye NF, et al. Acceptability of complementary foods and breads prepared from zinc-fortified cereal flours among young children and adults in Senegal. J Food Sci. 2011;76: S56-62.

40. Buzigi E, Pillay K, Siwela M. Caregiver perceptions and acceptability of a Provitamin a carotenoid, Iron and zinc rich complementary food blend prepared from common bean and pumpkin in rural Uganda. Nutrients. 2020;12.

41. FAO/WHO. Guidelines on formulated complementary foods for older infants and young children CAC/GL8-1991. Adopted in 1991. Amended in 2017. Revised in 2013. 2013. http://www.fao.org/fao-who-codexalimentarius/shproxy/en/?lnk=1\&url=https\%253A\%252F\%252Fworkspace.fao.org\%252 Fsites\%252Fcodex\%252FStandards\%252FCXG\%2B8-1991\%252FCXG_008e. pdf. Accessed 2 Mar 2020.

42. Uganda Bureau of Statistics. National Population and Housing Census 2014 Area specific profiles Kyankwanzi District. Kampala; 2017. https://www.ubos. org/wp-content/uploads/publications/2014CensusProfiles/KYANKWANZI.pdf. Accessed 7 Nov 2019

43. Uganda Bureau of Statistics, Inner City Fund. Uganda Demographic and Health Survey 2016. Kampala, Uganda and Rockville, Maryland, USA; 2018. https://dhsprogram.com/pubs/pdf/FR333/FR333.pdf

44. FAO. Guide to conducting participatory cooking demonstrations to improve complementary feeding practices. Manila: FAO; 2017. http://www.fao.org/3/ a-i7265e.pdf. Accessed 13 Dec 2019.

45. Bekele H, Turyashemererwa F. Feasibility and acceptability of food-based complementary feeding recommendations using trials of improved practices among poor families in rural eastern and Western Uganda. Food Sci Nutr. 2019;7:1311-27.

46. Rodriguez-Amaya D., Kimura M. Harvestplus handbook for carotenoid analysis. 2004. https://assets.publishing.service.gov.uk/media/57a08cbae5274 a31e00013d4/tech02.pdf. Accessed 9 Nov 2019.

47. Institute of Medicine. Dietary Reference intakes for Vitamin A, Vitamin K, Arsenic, Boron, Chromium, Copper, lodine, Iron, Manganese, Molybdenum, Nickel, Silicon, Vanadium, and Zinc. Washington, D.C: National Academy Press; 2001.

48. Santelli RE, De Almeida BM, De Santana OD, Cassella RJ, Ferreira SLC. Multivariate technique for optimization of digestion procedure by focussed microwave system for determination of $\mathrm{Mn}, \mathrm{Zn}$ and Fe in food samples using FAAS. Talanta. 2006:68:1083-8.

49. Lutter CK, Dewey KG. Proposed nutrient composition for fortified complementary foods. J Nutr. 2003;133:3011-20.

50. WHO, UNICEF. Recommendations for data collection, analysis and reporting on anthropometric indicators in children under 5 years old. Geneva: World Health Organization (WHO) and United Nations Children's Fund (UNICEF). 2019. https:/apps.who.int/iris/bitstream/handle/10665/324791/ 9789241515559-eng.pdf? sequence=1\&isAllowed=y. Accessed 21 Nov 2019 ..

51. Bauserman M, Lokangaka A, Kodondi KK, Gado J, Viera AJ, Bentley ME, et al. Caterpillar cereal as a potential complementary feeding product for infants and young children: nutritional content and acceptability. Matern Child Nutr. 2015;11(Suppl.4):214-20.

52. Konyole SO, Kinyuru JN, Owuor BO, Kenji GM, Onyango CA, Estambale BB, et al. Acceptability of Amaranth grain-based nutritious complementary foods with Dagaa fish (Rastrineobola argentea) and edible termites (Macrotermes subhylanus) compared to corn soy blend plus among young children/mothers dyads in Western Kenya. J Food Res. 2012;1:111-1120. https://doi.org/10.5539/jfr.v1n3p111.

53. Dewey KG, Brown KH. Update on technical issues concerning complementary feeding of young children in developing countries and implications for intervention programs. Food Nutr Bull. 2003;24:5-28.

54. Buzigi E, Pillay K, Siwela M. Effect of cooking locally available common bean (Obwelu) on iron and zinc retention, and pumpkin (sweet cream) on provitamin a carotenoid retention in rural Uganda. Accepted in. Food Sci Nutr. 2020. 
55. HarvestPlus. Provitamin A maize. 2012. https://www.harvestplus.org/sites/ default/files/HarvestPlus_Maize_Strategy.pdf. Accessed 18 Dec 2019.

56. HarvestPlus. Provitamin A sweet potato. 2007. https://www.harvestplus.org/ sites/default/files/HarvstPlus_Sweet_Potato_Strategy.pdf. Accessed 18 Dec 2019.

57. Petry N, Olofin I, Boy E, Angel MD, Rohner F. The effect of low dose Iron and zinc intake on child micronutrient status and development during the first 1000 days of life: a systematic review and meta-analysis. Nutrients. 2016; 8:11-22.

58. UNICEF. Vitamin A Supplementation: A Decade of progress. 2007. https:// www.unicef.org/publications/files/Nitamin_A_Supplementation.pdf. Accessed 6 Nov 2019.

59. Factfish. Vitamin A supplementation for Uganda. 2019. http://www.factfish com/statistic-country/uganda/vitamin a supplementation. Accessed 6 Nov 2019.

60. Mason J, Greiner T, Shrimpton R, Sanders D, Yukich J. Vitamin a policies need rethinking. Int J Epidemiol. 2015;44:283-92.

61. Blomhoff R, Green MH, Norum KR. Vitamin A : Physiological and biochemical processing absorption of carotenoids little quantitative data are available on the efficiency of intestinal absorption. Annu Rev Nutr. 1992;12: $37-57$.

62. Pedro MRA, Madriaga JR, Barba CVC, Habito RCF, Gana AE, Deitchler M, et al. The National Vitamin a Supplementation Program and subclinical vitamin a deficiency among preschool children in the Philippines. Food Nutr Bull. 2004;25:319-29.

63. Saini RK, Nile SH, Park SW. Carotenoids from fruits and vegetables: chemistry, analysis, occurrence, bioavailability and biological activities. Elsevier B.V.; 2015. doi:https://doi.org/10.1016/j.foodres.2015.07.047.

64. Kumar V, Sinha AK, Makkar HPS, Becker K. Dietary roles of phytate and phytase in human nutrition: a review. Food Chem. 2010;120:945-59. https:// doi.org/10.1016/j.foodchem.2009.11.052.

65. Fernandes AC, Nishida W, Da Costa Proença RP. Influence of soaking on the nutritional quality of common beans (Phaseolus vulgaris L.) cooked with or without the soaking water: A review. Int J Food Sci Technol. 2010;45:220918.

66. Miller LV, Hambidge KM, Krebs NF. Zinc absorption is not related to dietary Phytate intake in infants and young children based on modeling combined data from multiple studies. J Nutr. 2015;145:1763-9. https://doi.org/10.3945/ jn.115.213074.

\section{Publisher's Note}

Springer Nature remains neutral with regard to jurisdictional claims in published maps and institutional affiliations.

Ready to submit your research? Choose BMC and benefit from:

- fast, convenient online submission

- thorough peer review by experienced researchers in your field

- rapid publication on acceptance

- support for research data, including large and complex data types

- gold Open Access which fosters wider collaboration and increased citations

- maximum visibility for your research: over $100 \mathrm{M}$ website views per year

At BMC, research is always in progress.

Learn more biomedcentral.com/submissions 